\title{
Survei Tingkat Keterampilan Teknik Dasar Sepakbola Pemain Akademi Kelompok Usia 17 Tahun
}

\author{
Nur Samsudin Jaya Ilhami Putra ${ }^{1 \star}$, Eko Hariyanto ${ }^{2}$ \\ 1,2Jurusan Pendidikan Jasmani, Kesehatan dan Rekreasi, Fakultas IImu Keolahragaan, \\ Universitas Negeri Malang, Jalan Semarang No 5, Malang, Jawa Timur, 65145, Indonesia \\ *Penulis koresponden: nursamsudinjip@gmail.com, 089673869522
}

Artikel diterima: 2 Januari 2020; direvisi: 14 September 2020; disetujui: 18 September 2020

\begin{abstract}
This study aims to determine the level of basic technical skills of football players at the Arema Ngunut Tulungagung Academy. This study used a quantitative descriptive survey method with tests and measurements. Data analysis using percentage descriptive analysis. The results showed that the basic technical skills of football players at the Arema Ngunut Tulungagung AcademyU17 were in a moderate category. So it can be concluded that the basic technical skills of football on the Arema Ngunut Tulungagung Academy players have an average ability in the medium category.
\end{abstract}

Keyword: basic engineering, football, football academy

\begin{abstract}
Abstrak: Penelitian ini bertujuan untuk mengetahui tingkat keteram pilan teknik dasar sepakbola pemain Akademi Arema Ngunut Tulungagung. penelitian ini menggunakan metode survei deskriptif kuantitatif dengan tes dan pengukuran. Analisis data yang menggunakan analisis deskriptif persentase. Hasil penelitian menunjukkan keterampilan teknik dasar sepakbola pemain Akademi Arema Ngunut Tulungagung U17 tahun memiliki kategori sedang. Sehingga dapat disimpulkan bahwa kemampuan teknik dasar sepakbola pada pemain Akademi Arema Ngunut Tulungagung rata-rata memiliki kemampuan pada kategori sedang.
\end{abstract}

Kata kunci: teknik dasar, sepakbola, akademi sepakbola

\section{PENDAHULUAN}

Sepakbola adalah salah satu olahraga bola besar yang dimainkan oleh dua tim, yang masing-masing tim beranggotakan 11 orang pemain inti. Sepakbola dimainkan dengan cara dua tim yang saling berhadapan berusaha untuk mencetak gol sebanyak-banyaknya ke gawang lawan dan bertahan untuk mencegah lawan mencetak gol ke gawang yang dijaga. Lapangan sepakbola berbentuk persegi panjang dan dimainkan di atas rumput atau rumput sintetis. "Dalam sepakbola, suatu tim dikatakan memenangkan pertandingan jika dapat mencetak gol lebih banyak hingga pertandingan berakhir (Haugen, Tønnessen, Hisdal, \& Seiler, 2014; Verburgh, Scherder, Van Lange, \& Oosterlaan, 2014). Selain menjadi olahraga yang paling diminati, permainan ini sangat mudah untuk dilakukan dan juga menyenangkan. Bermain sepakbola dapat meningkatkan fungsi keterampilan dalam tubuh dan membuat psikis seseorang menjadi gembira dan senang. 
Selain itu, kebanyakan sebagian masyarakat juga sering mengisi waktu luang dengan bermain sepakbola, bahkan bermain sepakbola di lapangan ataupun di jalanan perkampungan masyarakat tersebut, sebab dari sepakbola dapat menambah rasa persaudaraan antar sesama masyarakat mulai dari anak-anak hingga orang dewasa. Banyaknya klub sepakbola untuk seorang pemain sepakbola sangat berpengaruh untuk peningkatan prestasi sepakbola, karena dengan adanya pelatihan sepakbola sejak usia dini, maka akan mencetak atlet atlet yang berkompeten untuk masa mendatang. Begitu juga di Tulungagung, yaitu Akademi Arema Ngunut, dan yang pasti dengan latihan yang intensif terdapat banyak atlet yang memiliki kemampuan atau keterampilan teknik dasar bermain sepakbola yang baik. Untuk dapat bermain sepakbola dengan baik, dipengaruhi oleh banyak faktor. Faktor fisik, teknik, taktik, dan mental merupakan komponen-komponen yang saling berkaitan dan mempengaruhi dalam meraih suatu prestasi. Untuk meraih prestasi, maka komponenkomponen tersebut harus dilatih dan dikembangkan secara maksimal. Antara lain beberapa teknik dasar bermain sepakbola yang harus dikuasai adalah passing, control, dribbling, shooting dan heading.

Dalam sepakbola, teknik dasar sangat diperlukan untuk bisa bermain dengan baik. Teknik dasar menjadi hal yang sangat penting dalam permainan sepakbola sebab dari teknik dasar inilah pemain dapat memainkan bola sesuai dengan apa yang diinginkannya. Jika seorang pemain tidak memiliki kemampuan teknik dasar yang baik, maka pemain tersebut akan kesulitan dalam bermain sepakbola, sebaliknya jika pemain memiliki teknik yang baik, permainannya juga baik pula. Teknik dasar merupakan keterampilan ataupun kemampuan yang dimiliki seorang pemain untuk melakukan gerakan yang berhubungan dengan sepakbola. Seorang pemain sepakbola harus menguasai teknik dasar dengan baik agar mengurangi keselahan dalam permainan (Dawud \& Hariyanto, 2020; Falahi \& Supriyadi, 2019). Setiap pemain sepakbola memiliki keterampilan bermain sepakbola yang berbeda beda, karena faktor bakat dan juga faktor latihan masing masing orang sangat berbeda dan menentukan kemampuan masing-masing individu tersebut. Untuk mengetahui tingkat keterampilan yang dimiliki pemain sepakbola dibutuhkan tes keterampilan bermain sepakbola yang digunakan untuk mengukur sejauh mana keterampilan atau kemampuan pemain tersebut dalam bermain sepakbola.

Maka dari itu, pembinaan usia muda dalam sepakbola harus terus dikembangkan untuk mencetak seorang pemain yang unggul dalam olahraga sepakbola yang merupakan olahraga yang paling populer di dunia. Selain itu pembinaan usia muda juga harus dilakukan pula di seluruh daerah di Indonesia guna menghasilkan pemain tim nasional yang sukses di masa yang akan datang. Tak hanya itu, dalam mencetak pemain yang unggul dalam sepakbola, pembinaan usia muda harus diperhatikan oleh pemerintah ataupun PSSI dengan cara mengadakan turnamen sepakbola antar kota ataupun antar daerah guna mengembangkan potensi atlit muda yang ada, turnamen atau kompetisi tersebut bisa dilaksanakan sesuai dengan kelompok umur di akademi sepakbola, diklat sepakbola, ataupun sekolah sepakbola mulai dari usia 10 tahun hingga senior. Jika turnamen atau kompetisi berjalan maka jam terbang atau pengalaman pemain akan bertambah, sehingga akan banyak bibit-bibit pemain sepakbola bermunculan dan dapat memudahkan pemandu bakat dalam mencari pemain yang potensial yang nantinya akan menjadi pemain yang sukses dimasa yang akan datang.

Selain itu, dalam pemberian latihan yang tepat dan bermanfaat juga dapat membantu para atlit dalam mengembangkan potensi bermain sepakbola yang ada pada dirinya. Latihan teknik dasar dapat dilakukan secara terus menerus dan bertahap agar kemampuan para atlit dapat meningkat. Selain itu peran pelatih juga dibutuhkan dalam memberikan motivasi pada atlitnya dengan memberikan instruksi agar pemain menambah porsi latihan sendiri dirumah, tidak hanya mengandalkan latihan yang diberikan pada saat latihan di akademi sepakbola, sekolah sepakbola, ataupun diklat sepakbola, sebab kemampuan atlit dapat berkembang jika ada kemauan berlatih yang tinggi pada diri atlit tersebut. Peran pelatih juga diharapkan untuk memberikan dorongan motivasi semangat untuk latihan dan memberikan larangan-larangan yang dapat menurunkan performa bermain sepakbola yang ada pada para diri pemain tersebut.

\section{Sepakbola}

Sepakbola merupakan salah satu cabang olahraga yang populer dan digemari oleh masyarakat di dunia. Hal tersebut bisa dilihat dari perkembangan olahraga sepakbola yang begitu pesat dengan antusiasnya masyarakat yang melakukan olahraga sepakbola baik anak-anak, remaja, bahkan orang dewasa. Olahraga ini termasuk kedalam olahraga permainan bola besar yang dimainkan secara beregu dan mengandalkan kesolidan tim (Brophy et al., 2012; Pfirrmann, Herbst, Ingelfinger, Simon, \& Tug, 2016). Sepakbola bertujuan untuk mencetak gol sebanyak-banyaknya dengan menggunakan bola kulit berukuran 27-28 dan dimainkan oleh 2 regu yang masing-masing beranggotakan 11 orang (Bizzini, Hancock, \& Impellizzeri, 2012; García, 
García-Zapico, Patterson, \& Iglesias-Gutiérrez, 2014). Sepakbola merupakan permainan tim yang setiap pemainnya harus bekerjasama dan kompak agar menghasilkan sebuah kemenangan. Sepakbola dapat dimainkan oleh siapa saja mulai dari anak-anak hingga orang dewasa (Maher, Hutchison, Cusimano, Comper, \& Schweizer, 2014; Morgans, Orme, Anderson, \& Drust, 2014). Olahraga ini tidak memandang gender dalam hal permainannya, hal ini ditunjukkan dalam perkembangan sepakbola saat ini yang banyak melahirkan atlitatlit sepakbola wanita yang cukup handal, dan juga tim-tim sepakbola wanita professional di seluruh penjuru dunia tak terkecuali di Indonesia.

\section{Keterampilan Teknik Dasar Sepakbola}

Dalam permainan sepakbola seorang pemain harus memiliki kemampuan dasar dalam bermain sepakbola dan dituntut untuk belajar mengenai teknik dasar sepakbola agar dapat bermain dengan sebaik-baiknya. keterampilan dasar bermain sepakbola adalah kemampuan menerapkan berbagi keterampilan yang berfaedah yang ditunjukkan dengan tingkat kemahiran dan derajat keberhasilan yang konsisten dalam bermain sepakbola (Smith, Coutts, et al., 2016; Turner \& Stewart, 2014). Selain itu, teknik dasar sepakbola merupakan keterampilan ataupun kemampuan yang dimiliki seorang pemain untuk melakukan gerakan yang berhubungan dengan sepakbola (Lew et al., 2012; Slimani et al., 2016).

\section{Keterampilan Mengumpan Bola (Passing)}

Passing merupakan suatu teknik dasar pada sepakbola dimana bola berpindah dari kaki pemain yang satu ke pemain yang lainnya dalam tim itu sendiri (Clemente, Lourenço Martins, \& Mendes, 2014; Padua et al., 2015). Passing adalah momentum teknik dasar yang dilakukan untuk memindahkan bola dari pemain satu ke pemain yang lain (Oliveira et al., 2017; Read, Oliver, De Ste Croix, Myer, \& Lloyd, 2016). Passing dalam sepakbola dibedakan menjadi 2 macam yaitu: (1) Passing menggunakan kaki bagian dalam, (2) Passing menggunakan punggung kaki (Grooms, Palmer, Onate, Myer, \& Grindstaff, 2013; Van Beijsterveldt et al., 2012).

\section{Keterampilan Menghentikan Bola (Controlling)}

Menghentikan bola dalam permainan sepakbola sangat dibutuhkan oleh setiap pemain. Menghentikan bola yang baik dari setiap pemain akan memudahkan pemain dalam melakukan passing kembali dan menciptakan peluang atau mengumpan dengan cepat ke teman saat bermain. Hal ini sependapat dengan pernyataan yang mendefinisikan bahwa menghentikan bola adalah teknik yang digunakan bersamaan dengan teknik menendang bola, mengatur tempo permainan, mempermudah untuk melakukan passing dan mengatur laju permainan (Grooms et al., 2013; Stubbe et al., 2015).

\section{Keterampilan Menggiring Bola(Dribbling)}

Dribbling merupakan salah satu teknik yang diperlukan dalam sepakbola, sebab melalui dribbling ini pemain dapat leluasa memindahkan bola dari satu titik ke titik yang lainnya dengan cara berlari membawa bola. Teknik dribbling biasanya digunakan oleh pemain dalam mengelabui musuh saat permainan berlangsung. Hal ini sesuai dengan pernyataan bahwa dribbling merupakan keterampilan dalam bermain sepakbola yang dimiliki oleh pemain dengan tujuan untuk mengecoh lawan (Dai, Mao, Garrett, \& Yu, 2014; Rossi et al., 2018).

\section{Keterampilan Menembak Bola (Shooting)}

Shooting merupakan teknik dasar yang harus dikuasai oleh setiap pemain, teknik ini merupakan cara untuk memasukkan bola ke gawang lawan. Shooting merupakan kemampuan yang dimiliki oleh pemain sepakbola dengan gerakan menembak bola sekuat tenaga kearah gawang lawan, dengan tujuan untuk mencetak gol (Huijgen et al., 2015; Smith, Zeuwts, et al., 2016). Teknik shooting ini dapat dilakukan disemua sisi lapangan, tetapi yang lebih dominan adalah mendekati atau di dalam kotak pinalti lawan, sebab hal itu lebih berpeluang untuk terciptanya gol.

\section{Keterampilan Menyundul Bola (Heading)}

Hal penting dalam sepakbola dimana kepala menjadi andalan ketika berduel di depan gawang lawan adalah heading. Heading atau menyundul adalah gerakan dimana seseorang menggunakan bagian kepalanya untuk impact dengan bola entah itu melakukan passing ataupun untuk mencetak gol yang diarahkan ke gawang lawan (Rematas, Kemelmacher-Shlizerman, Curless, \& Seitz, 2018; Van Den Tillaar \& Ulvik, 2014). Teknik heading dapat dilakukan oleh semua pemain yang ada dalam permainan sepakbola, gerakan ini dilakukan jika bola berada di atas kepala kita sehingga mau tidak mau yang kita lakukan adalah mengubah atau 
menghentikan arah bola menggunakan kepala. Persyaratan saat melakukan teknik heading ini adalah saat akan menyundul bola perhatian harus fokus pada bola dan bola mengenai dahi pada kepala (Nédélec et al., 2012; Silva, Nassis, \& Rebelo, 2015).

Berdasarkan latar belakang yang telah dikemukakan di depan, teknik dasar sepakbola pada pemain Akademi Arema Ngunut Tulungagung masih perlu dikaji lebih lanjut. Sehingga peneliti melakukan pengamatan dan memilih Akademi Arema Ngunut Tulungagung yang terletak di Jln. Demuk No.39 LK.IV Ngunut. Dengan demikian, penulis akan melakukan penelitian yang berjudul "Survei Tingkat Keterampilan Teknik Dasar Sepakbola Pemain Akademi Arema Ngunut Tulungagung Kelompok Usia 17 Tahun”.

\section{METODE}

Penelitian ini merupakan penelitian deskriptif kuantitatif dengan metode analisis deskriptif presentase. Penelitian ini berusaha untuk memaparkan atau mendeskripsikan peristiwa yang terjadi di masa kini. Subyek yang digunakan dalam penelitian ini pemain Akademi Arema Ngunut Tulungagung yang berjumlah 17 pemain. Teknik pengumpulan data pada penelitian ini menggunakan tes dan pengukuran. Tempat yang akan digunakan pada penelitian ini adalah Lapangan Akademi Arema Ngunut Tulungagung yang terletak di Jln. Demuk No.39 LK.IV Ngunut. Waktu penelitian dilaksanakan pada tgl 24 bulan Oktober tahun 2019.

Penelitian ini menggunakan, yakni instrumen tes yaitu tes keterampilan olahraga. Tes keterampilan olahraga merupakan tes yang digunakan untuk mengetahui kemampuan atau keterampilan olahraga yang dimiliki oleh individu/seseorang. Tes keterampilan sepakbola ini meliputi (1) passing dan controlling, (2) dribbling, (3) shooting, dan (4) heading (Jamshed, 2014; Leguina, 2015).

Analisis data yang digunakan adalah analisis deskriptif kuantitatif dengan metode analisis perhitungan statistik menggunakan analisis deskriptif persentase. Data yang telah terkumpul dari hasil tes keterampilan merupakan data kasar kemudian diubah menjadi nilai dengan cara mengkonversikan setiap butir tes dengan menggunakan tabel penilaian keterampilan teknik dasar sepakbola. Data diolah dengan cara hasil data pengukuran tes keterampilan teknik dasar sepakbola.

HASIL

Tes Mengumpan Dan Menghentikan Bola (passing \& controlling)

Tabel 1 Distribusi Frekuensi Data Hasil Tes Passing \& Controlling pemain Akademi Arema Ngunut Tulungagung $\mathrm{U} 17$ Tahun

\begin{tabular}{ccccc}
\hline No & Nilai & Kategori & Frekuensi & Persentase \\
\hline 1 & $\geq 61$ & Baik & 2 & $11,80 \%$ \\
2 & $52-60$ & Cukup & 4 & $23,50 \%$ \\
3 & $46-52$ & Sedang & 0 & $0,0 \%$ \\
4 & Kurang & 11 & $64,70 \%$ \\
5 & $37-45$ & Kurang sekali & 0 & $0,0 \%$ \\
\hline 6 & $\leq 36$ & & 17 & $100 \%$ \\
\hline
\end{tabular}

Dari Tabel 1 di atas, diketahui bahwa keterampilan passing dan controlling pemain Akademi Arema Ngunut Tulungagung sebagian besar berada di kategori "kurang" .

Hasil Tes Keterampilan menggiring Bola (Dribbling)

Tabel 2 Distribusi Frekuensi Data Hasil Tes Dribbling Pemain Akademi Arema Ngunut Tulungagung U17 Tahun

\begin{tabular}{ccccc}
\hline No & Nilai & Kategori & Frekuensi & Persentase \\
\hline 1 & $\geq 61$ & Baik & 2 & $11.80 \%$ \\
2 & $52-60$ & Cukup & 6 & $35.30 \%$ \\
3 & $46-52$ & Sedang & 2 & $11.80 \%$
\end{tabular}




\begin{tabular}{ccccc}
4 & $37-45$ & Kurang & 5 & $29.40 \%$ \\
5 & $\leq 36$ & Kurang sekali & 2 & $11.80 \%$ \\
\hline 6 & Jumlah & & 17 & $100 \%$ \\
\hline
\end{tabular}

Data Tabel 2 di atas, dapat diketahui bahwa keterampilan dribbling pemain Akademi Arema Ngunut Tulungagung berada dalam kategori"cukup"

\section{Hasil Tes Keterampilan Menanduk Bola (Heading)}

Tabel 3 Distribusi Frekuensi Data tes Heading Pemain Akademi Arema Ngunut Tulungagung U 17 Tahun

\begin{tabular}{ccccc}
\hline No & Nilai & Kategori & Frekuensi & Persentase \\
\hline 1 & $\geq 61$ & Baik & 4 & $23.50 \%$ \\
2 & $52-60$ & Cukup & 7 & $41.20 \%$ \\
3 & $46-52$ & Sedang & 0 & $0.0 \%$ \\
4 & Kurang & 5 & $29.40 \%$ \\
5 & $\leq 36-45$ & Kurang sekali & 1 & $5.90 \%$ \\
\hline 6 & Jumlah & & 17 & $100 \%$ \\
\hline
\end{tabular}

Data Tabel 3 di atas, dapat diketahui bahwa keterampilan heading pemain Akademi Arema Ngunut Tulungagung berada dalam kategori"cukup"

\section{Hasil Tes Keterampilan Menembak Bola (Shooting)}

Tabel 4 Distribusi Frekuensi Data Hasil Tes Shooting Pemain Akademi Arema Ngunut Tulungagung U17 Tahun

\begin{tabular}{ccccc}
\hline No & Nilai & Kategori & Frekuensi & Persentase \\
\hline 1 & $\geq 61$ & Baik & 3 & $17.60 \%$ \\
2 & $52-60$ & Cukup & 7 & $41.20 \%$ \\
3 & $46-52$ & Sedang & 4 & $23.50 \%$ \\
4 & $37-45$ & Kurang & 1 & $5.90 \%$ \\
5 & $\leq 36$ & Kurang sekali & 2 & $11.80 \%$ \\
\hline 6 & Jumlah & & 17 & $100 \%$ \\
\hline
\end{tabular}

Dari Tabel 4 di atas, diperoleh Keterampilan shooting pemain Akademi Arema Ngunut Tulungagung dalam kategori"cukup"

\section{Hasil Tes Keseluruhan Keterampiulan Teknik Dasar Sepakbola}

Tabel 5 Distribusi frekuensi Hasil Data Keseluruhan Tes keterampilan sepakbola pemain Akademi Arema Ngunut Tulungagung U17 Tahun

\begin{tabular}{ccccc}
\hline No & Nilai & Kategori & Frekuensi & Persentase \\
\hline 1 & $\geq 61$ & Baik & 2 & $11.80 \%$ \\
2 & $52-60$ & Cukup & 3 & $17.60 \%$ \\
3 & $46-52$ & Sedang & 9 & $52.90 \%$ \\
4 & $37-45$ & Kurang & 3 & $17.60 \%$ \\
5 & $\leq 36$ & Kurang sekali & 0 & $0.0 \%$ \\
\hline 6 & Jumlah & & 17 & $100 \%$ \\
\hline
\end{tabular}

Dari Tabel 4.5 di atas, diperoleh hasil seluruh Keterampilan teknik dasar sepakbola pemain Akademi Arema Ngunut Tulungagung dalam kategori"sedang", dimana secara rinci dapat diperjelas yaitu terdapat, 2 pemain dalam kategori "baik sekali", 3 pemain dalam kategori "cukup", 9 pemain dalam kategori "sedang", dan 3 pemain dengan kategori "kurang".

Berdasarkan uraian data diatas, secara keseluruhan keterampilan dasar bermain sepakbola yang dimiliki pemain Akademi Arema Ngunut Tulungagung U17 tahun dalam hal passing \& controlling, dribbling, heading, 
dan shooting sebagian besar adalah pada kategori "sedang". Secara rinci dapat diperjelas yaitu terdapat, 2 pemain dalam kategori "baik sekali", 3 pemain dalam kategori "cukup", 9 pemain dalam kategori "sedang", dan 3 pemain dengan kategori "kurang". Perbedaan hasil kemampuan teknik dasar sepakbola pada kategori "baik sekali" jika pemain mendapat skor rata-rata lebih dari 61, pada kategori "cukup" jika pemain mendapat skor rata-rata 52-60, pada kategori "sedang" jika pemain mendapat skor rata-rata 46-52, pada kategori "kurang" jika pemain mendapat skor rata-rata dari 37-45, dan pada kategori "kurang sekali" apabila pemain mendapatkan skor rata-rata kurang dari 36.

\section{PEMBAHASAN}

\section{Keterampilan Mengunpan dan Menghentikan Bola (Passing \& Controlling)}

Hasil penelitian pada keterampilan menendang dan menghentikan bola, diperoleh hasil pemain Akademi Arema Ngunut Tulungagung yaitu 11 pemain dengan persentase (64,70\%) termasuk kategori"Kurang". Artinya kemampuan teknik passing \& controlling pemain Akademi Arema Ngunut Tulungagung berada pada kategori "sedang".

Hal yang menyebabkan kemampuan dasar passing dan controlling pada pemain Akademi Arema Ngunut Tulungagung kelompok usia 17 tahun dengan kategori "sedang" adalah (1) kurang menguasainya teknik dasar sepakbola dalam hal passing (2) pada saat pelaksanaan tes, beberapa pemain tidak meperhatikan perkenaan kaki yang digunakan passing sehingga bola bergulir secara tidak terarah dan tidak memantul secara maksimal pada tembok sasaran, hal itu mengakibatkan bola menjadi kembali kearah pemain tidak terarah . (3) banyak bola yang keluar dari batas lintasan, sehingga pemain banyak kehilangan waktu untuk mengambil kembali bola (4) pemain melaksanakan tes passing di depan garis batas yang ditentukan, hal itu seharusnya tidak diperkenankan sehingga poin tidak sah (5) para pemain kurang konsentrasi ketika melakukan tes menendang dan menghentikan bola, teknik passing ini sangat diperlukan pada permainan sepakbola karena bola dapat berpindah dari kaki satu pemain ke pemain lainnya dalam tim itu sendiri melalui teknik passing ini.

\section{Keterampilan Menggiring Bola (Dribbling)}

Hasil penelitian dan analisis data yang telah dijelaskan pada bab IV pada keterampilan menggiring bola Akademi Arema Ngunut Tulungagung diperoleh hasil yaitu 2 pemain dengan persentase $(11,80 \%)$ termasuk kategori "baik", 6 pemain $(35,30 \%), 2$ pemain $(11.80 \%)$ dalam kategori "sedang", 5 pemain $(29,40 \%)$ termasuk kategori "kurang", dan 2 pemain dengan persentase $(11,80 \%)$ dalam kategori "kurang sekali". Artinya kemampuan teknik dribbling pemain Akademi Arema Ngunut Tulungagung berada dalam kategori "cukup". Hal-hal yang mempengaruhi kemampuan dasar dribbling pada pemain Akademi Arema Ngunut Tulungagung kelompok usia 17 tahun kurang maksimal adalah (1) kurang menguasainya teknik dasar sepakbola dalam hal dribbling, (2) kurangnya konsentrasi pemain ketika pelaksanaan tes, (3) pada saat pelaksanaan tes, beberapa pemain tergesa-gesa, bola keluar dari jalur lintasan tes dribbling, sehingga pemain kesulitan untuk mengontrol bola.

\section{Keterampilan Menanduk Bola(Heading)}

Hasil penelitian pada keterampilan menyundul bola, diperoleh hasil pemain Akademi Arema Ngunut Tulungagung yaitu 4 pemain $(23,50 \%)$ dalam kategori "baik", 7 pemain $(41,20 \%)$ termasuk kategori "cukup", 5 pemain $(29,40 \%)$ dalam kategori "kurang", 1 pemain $(5,90 \%)$ dengan kategori "kurang sekali", dan tidak ada pemain dengan kategori "sedang". Artinya bedasarkan hasil penelitian menunjukan bahwa pemain Akademi Arema Ngunut Tulungagung memiliki kemapuan teknik heading dengan kategori "cukup". Hal ini berbanding terbalik dengan penelitian Erlangga \& Widodo (2013:4) menyatakan bahwa kemampuan heading pada pemain SSB Mitra Surabaya memiliki kategori yang "baik". Kemampuan heading sangat diperlukan setiap pemain dalam bermain sepakbola, dimana teknik ini digunakan untuk memasukan bola ke gawang lawan atau untuk menghalau bola saat berada di daerah pertahanan. Untuk meningkatkan kemampuan heading dalam sepakbola dapat dilakukan dengan cara melakukan latihan heading secara berpasangan. Hal ini sependapat dengan penelitian yang dilakukan oleh Rahmat \& Hermanzoni (2019) yang menyatakan bahwa latihan heading berpasangan dapat meningkatkan kualitas teknik menanduk bola secara menyeluruh, 13 orang (59.9) memiliki skor heading pada berada pada kategori baik, saat melakukan latihan heading berpasangan. 


\section{Keterampilan Menembak Bola(Shooting)}

Hasil penelitian pada keterampilan menendang dan menghentikan bola, diperoleh hasil pemain Akademi Arema Ngunut Tulungagung yaitu 3 pemain $(17,60 \%)$ termasuk kategori "baik", 7 pemain $(41,20 \%)$ dalam kategori "cukup", 4 pemain $(23,50)$ dalam kategori "sedang", 1 pemain $(5,90 \%)$ dalam kategori "kurang", dan 2 pemain (11,80\%), termasuk kategori "kurang sekali". Berdasarkan hasil penelitian di Akademi Arema Ngunut Tulungagung menunjukkan bahwa rata-rata pemain memiliki keterampilan shooting dalam kategori cukup, hal ini dikarenakan pelatih kurang dalam memberikan materi yang berkaitan dengan shooting pada permainan sepakbola. Pada saat peneliti memberikan tes, para pemain sangat antusias untuk mengikuti setiap prosedur tes yang telah disediakan dan dipersiapkan oleh peneliti, karena dengan mengikuti tes tersebut, pemain juga mendapatkan ilmu baru serta dapat mengukur kemampuan shooting setiap pemain.

Teknik shooting ini harus dikuasai oleh setiap pemain dimana diperlukan dalam permainan sepakbola dalam hal urusan mencetak gol ke gawang lawan sebanyak-banyaknya guna memenangkan pertandingan. Untuk meningkatkan kemampuan shooting dalam sepakbola, dapat dilakukan dengan cara menembak bola ke gawang secara berulang-ulang, hal ini selaras dengan penelitian yang dilakukan oleh Istofian \& Amiq (2016:1) bahwa untuk meningkatkan kemampuan shooting dapat dilakukan dengan cara metode drill atau menembak bola secara berulang-ulang dengan sasaran berupa gawang.

\section{Hasil Seluruh Tes Keterampilan Teknik Dasar Sepakbola}

Berdasarkan hal tersebut peneliti melakukan pengumpulan data dari tes keterampilan yang terdiri dari 4 butir tes yaitu: tes passing \& controlling, tes dribbling, tes heading, dan tes shooting, terdapat kategori "baik" sebanyak 2 pemain dengan persentase $(11,80 \%)$, untuk kategori "cukup" sebanyak 3 pemain dengan persentase (17,60\%), kategori "sedang" sebanyak 9 pemain dengan persentase $(52,90 \% \%)$, dan kategori "kurang" sebanyak 3 pemain dengan persentase (17,60\%). Hal ini memberikan gambaran bahwa pemain Akademi Arema Ngunut Tulungagung kelompok usia 17 tahun rata-rata memiliki kemampuan dasar bermain sepakbola pada level sedang. Meskipun rata-rata pemain Akademi Arema Ngunut Tulungagung kelompok usia 17 tahun memiliki kategori kemampuan bermain sepakbola yang sedang, namun ada beberapa pemain yang memiliki kemampuan bermain sepakbola dengan kategori "baik", "cukup" dan "kurang".Dengan demikian hasil penelitian secara keseluruhan dapat disimpulkan tingkat keterampilan teknik dasar sepakbola di Akademi Arema Ngunut Tulungagung dinyatakan "sedang" sebanyak 9 pemain dengan persentase $(52,90 \%)$. Selanjutnya hal ini dapat memberikan pertimbangan terhadap pelatih untuk menambah latihan, agar dapat meningkatkan kualitas teknik dasar sepakbola setiap pemain Akademi Arema Ngunut Tulungagung.

\section{KESIMPULAN}

Berdasarkan penelitian yang dilakukan pada pemain Akademi Arema Ngunut Tulungagung kelompok usia 17 tahun diperoleh hasil kemampuan teknik dasar sepakbola dengan rincian sebagai berikut:

(1)Hasil penelitian dan analisis data tes passing dan controlling pemain Akademi Arema Ngunut Tulungagung dalam kategori "kurang". (2). Hasil penelitian dan analisis data tes dribbling pemain Akademi Arema Ngunut Tulungagung dalam kategori "cukup". (3). Hasil penelitian dan analisis data tes heading pemain Akademi Arema Ngunut Tulungagung dalam kategori "cukup". (4). Hasil penelitian dan analisis data shooting pemain Akademi Arema Ngunut Tulungagung dalam kategori "cukup". (5). Hasil penelitian dan analisis data dari seluruh tes teknik dasar pemain Akademi Arema Ngunut Tulungagung dalam kategori "sedang", dengan data sebagai berikut: terdapat kategori "baik" sebanyak 2 pemain dengan persentase $(11,80 \%)$, untuk kategori "cukup" sebanyak 3 pemain dengan persentase $(17,60 \%)$, kategori "sedang" sebanyak 9 pemain dengan persentase $(52,90 \% \%)$, dan kategori "kurang" sebanyak 3 pemain dengan persentase $(17,60 \%)$.

Berdasarkan hasil penelitian, dapat disimpulkan bahwa kemampuan teknik dasar sepakbola pada pemain Akademi Arema Ngunut Tulungagung kelompok usia 17 tahun rata-rata memiliki kemampuan pada kategori "sedang". Disarankan kepada pelatih untuk mengevaluasi keterampilan teknikdasar setiap pemain dan untuk pemain untuk melakukan latihan secara rutin agar kemampuan teknik dasar yang dimiliki dapat meningkat. 


\section{Ucapan Terimakasih}

Peneliti menyadari, bahwa dalam penulisan skripsi ini tidak akan selesai tanpa bantuan dari berbagai pihak. Sehingga dikesempatan yang baik ini peneliti mengucapkan terimakasih yang sebesar-besarya kepada Dr. Sapto Adi, M.Kes., selaku Dekan Fakultas IImu Keolahragaan Universitas Negeri Malang, yang telah memberikan kesempatan bagi peneliti untuk menyelesaikan pendidikan dan menempuh jenjang sarjana di FIK UM, Dr. dr. Moch. Yunus, M.Kes., sebagai Wakil Dekan I Fakultas IImu Keolahragaan yang telah membantu dan memberikan izin dalam proses penelitian, Dr. Lokananta Teguh Hari Wiguno, M.Kes., selaku Ketua Jurusan Pendidikan Jasmani dan Kesehatan Fakultas IImu Keolahragaan, Dr. Eko Hariyanto, M.Pd., selaku Dosen Pembimbing I yang telah meluangkan waktu memberikan bimbingan, memberikan motivasi, masukan, dan saran-saran yang sangat berharga bagi peneliti, kepada pihak Akademi Arema Ngunut Tulungagung yangmemberikan izin bagi peneliti untuk melaksanakan penelitian.

\section{DAFTAR PUSTAKA}

Bizzini, M., Hancock, D., \& Impellizzeri, F. (2012). Suggestions from the field for return to sports participation following anterior cruciate ligament reconstruction: Soccer. Journal of Orthopaedic and Sports Physical Therapy. https://doi.org/10.2519/jospt.2012.4005

Brophy, R. H., Schmitz, L., Wright, R. W., Dunn, W. R., Parker, R. D., Andrish, J. T., .. Spindler, K. P. (2012). Return to play and future $A C L$ injury risk after $A C L$ reconstruction in soccer athletes from the multicenter orthopaedic outcomes network (MOON) group. American Journal of Sports Medicine. https://doi.org/10.1177/0363546512459476

Clemente, F. M., Lourenço Martins, F. M., \& Mendes, R. S. (2014). Developing aerobic and anaerobic fitness using small-sided soccer games: Methodological proposals. Strength and Conditioning Journal. https://doi.org/10.1519/SSC.0000000000000063

Dai, B., Mao, D., Garrett, W. E., \& Yu, B. (2014). Anterior cruciate ligament injuries in soccer: Loading mechanisms, risk factors, and prevention programs. Journal of Sport and Health Science. https://doi.org/10.1016/j.jshs.2014.06.002

Dawud, V. W. G. W. A. N., \& Hariyanto, E. (2020). Survei Kondisi Fisik Pemain Sepakbola U 17. Sport Science and Health, 2(4), 224-231. Retrieved from http://journal2.um.ac.id/index.php/jik/index

Erlangga, S. Y., \& Widodo, A. (2013). Survei Kondisi Fisik dan Keterampilan Teknik Dasar Sepakbola (Study pada Klub Sepakbola Mitra Surabaya). Jurnal Kesehatan Olahraga, 1(2), 1-7.

Falahi, S. A., \& Supriyadi. (2019). Pengembangan Variasi Model-Model Latihan Agility Sepakbola. Sport Science and Health, 1(2), 139-145. Retrieved from http://journal2.um.ac.id/index.php/jik/index

García, P. M. R., García-Zapico, P., Patterson, Á. M., \& Iglesias-Gutiérrez, E. (2014). Nutrient intake and food habits of soccer players: Analyzing the correlates of eating practice. Nutrients. https://doi.org/10.3390/nu6072697

Grooms, D. R., Palmer, T., Onate, J. A., Myer, G. D., \& Grindstaff, T. (2013). Soccer-specific warm-up and lower extremity injury rates in collegiate male soccer players. Journal of Athletic Training. https://doi.org/10.4085/1062-6050-48.4.08

Haugen, T. A., Tønnessen, E., Hisdal, J., \& Seiler, S. (2014). The role and development of sprinting speed in soccer. International Journal of Sports Physiology and Performance. https://doi.org/10.1123/IJSPP.2013-0121

Huijgen, B. C. H., Leemhuis, S., Kok, N. M., Verburgh, L., Oosterlaan, J., Elferink-Gemser, M. T., \& Visscher, C. (2015). Cognitive functions in elite and sub-elite youth soccer players aged 13 to 17 years. PLoS ONE. https://doi.org/10.1371/journal.pone. 0144580

Istofian, R. S., \& Amiq, F. (2016). Metode Drill untuk Meningkatkan Teknik Menendang Bola (Shooting) dalam Permainan Sepakbola Usia 13-14 Tahun. Jurnal Kepelatihan Olahraga, 1(1), 105-113.

Jamshed, S. (2014). Qualitative research method-interviewing and observation. Journal of Basic and Clinical 
Pharmacy. https://doi.org/10.4103/0976-0105.141942

Leguina, A. (2015). A primer on partial least squares structural equation modeling (PLS-SEM). International Journal of Research \& Method in Education. https://doi.org/10.1080/1743727x.2015.1005806

Lew, M. L., Kasasbeh, A. S., Baird, L. C., Amene, C., Skeen, J., \& Marshall, L. (2012). Concussions in soccer: A current understanding. World Neurosurgery. https://doi.org/10.1016/j.wneu.2011.10.032

Maher, M. E., Hutchison, M., Cusimano, M., Comper, P., \& Schweizer, T. A. (2014). Concussions and heading in soccer: A review of the evidence of incidence, mechanisms, biomarkers and neurocognitive outcomes. Brain Injury. https://doi.org/10.3109/02699052.2013.865269

Morgans, R., Orme, P., Anderson, L., \& Drust, B. (2014). Principles and practices of training for soccer. Journal of Sport and Health Science. https://doi.org/10.1016/j.jshs.2014.07.002

Nédélec, M., McCall, A., Carling, C., Legall, F., Berthoin, S., \& Dupont, G. (2012). Recovery in Soccer. Sports Medicine. https://doi.org/10.2165/11635270-000000000-00000

Oliveira, C., Ferreira, D., Caetano, C., Granja, D., Pinto, R., Mendes, B., \& Sousa, M. (2017). Nutrition and Supplementation in Soccer. Sports. https://doi.org/10.3390/sports5020028

Padua, D. A., DiStefano, L. J., Beutler, A. I., De La Motte, S. J., DiStefano, M. J., \& Marshall, S. W. (2015). The landing error scoring system as a screening tool for an anterior cruciate ligament injury-prevention program in elite-youth soccer athletes. Journal of Athletic Training. https://doi.org/10.4085/1062-605050.1.10

Pfirrmann, D., Herbst, M., Ingelfinger, P., Simon, P., \& Tug, S. (2016). Analysis of injury incidences in male professional adult and elite youth soccer players: A systematic review. Journal of Athletic Training. https://doi.org/10.4085/1062-6050-51.6.03

Rahmat, C., \& Hermanzoni. (2019). Pengaruh Metode Latihan Individual dan Metode Latihan Berpasangan Terhadap Kemampuan Heading. Jurnal Patriot, 1(1), 116-122.

Read, P. J., Oliver, J. L., De Ste Croix, M. B. A., Myer, G. D., \& Lloyd, R. S. (2016). Neuromuscular Risk Factors for Knee and Ankle Ligament Injuries in Male Youth Soccer Players. Sports Medicine. https://doi.org/10.1007/s40279-016-0479-z

Rematas, K., Kemelmacher-Shlizerman, I., Curless, B., \& Seitz, S. (2018). Soccer on Your Tabletop. Proceedings of the IEEE Computer Society Conference on Computer Vision and Pattern Recognition. https://doi.org/10.1109/CVPR.2018.00498

Rossi, A., Pappalardo, L., Cintia, P., laia, F. M., Fernàndez, J., \& Medina, D. (2018). Effective injury forecasting in soccer with GPS training data and machine learning. PLOS ONE. https://doi.org/10.1371/journal.pone.0201264

Silva, J. R., Nassis, G. P., \& Rebelo, A. (2015). Strength training in soccer with a specific focus on highly trained players. Sports Medicine - Open. https://doi.org/10.1186/s40798-015-0006-z

Slimani, M., Bragazzi, N. L., Tod, D., Dellal, A., Hue, O., Cheour, F., ... Chamari, K. (2016). Do cognitive training strategies improve motor and positive psychological skills development in soccer players? Insights from a systematic review. Journal of Sports Sciences. https://doi.org/10.1080/02640414.2016.1254809

Smith, M. R., Coutts, A. J., Merlini, M., Deprez, D., Lenoir, M., \& Marcora, S. M. (2016). Mental fatigue impairs soccer-specific physical and technical performance. Medicine and Science in Sports and Exercise. https://doi.org/10.1249/MSS.0000000000000762

Smith, M. R., Zeuwts, L., Lenoir, M., Hens, N., De Jong, L. M. S., \& Coutts, A. J. (2016). Mental fatigue impairs soccer-specific decision-making skill. Journal of Sports Sciences. https://doi.org/10.1080/02640414.2016.1156241

Stubbe, J. H., Van Beijsterveldt, A. M. M. C., Van Der Knaap, S., Stege, J., Verhagen, E. A., Van Mechelen, W., \& Backx, F. J. G. (2015). Injuries in professional male soccer players in the Netherlands: A prospective cohort study. Journal of Athletic Training. https://doi.org/10.4085/1062-6050-49.3.64 
Turner, A. N., \& Stewart, P. F. (2014). Strength and conditioning for soccer players. Strength and Conditioning Journal. https://doi.org/10.1519/SSC.0000000000000054

Van Beijsterveldt, A. M. C., Van De Port, I. G. L., Krist, M. R., Schmikli, S. L., Stubbe, J. H., Frederiks, J. E., \& Backx, F. J. G. (2012). Effectiveness of an injury prevention programme for adult male amateur soccer players: A cluster-randomised controlled trial. British Journal of Sports Medicine. https://doi.org/10.1136/bjsports-2012-091277

Van Den Tillaar, R., \& Ulvik, A. (2014). Influence of instruction on velocity and accuracy in soccer kicking of experienced soccer players. Journal of Motor Behavior. https://doi.org/10.1080/00222895.2014.898609

Verburgh, L., Scherder, E. J. A., Van Lange, P. A. M., \& Oosterlaan, J. (2014). Executive functioning in highly talented soccer players. PLOS ONE. https://doi.org/10.1371/journal.pone.0091254 